\title{
Koronavirüs (COVID-19) salgını süresince zorunlu uzaktan eğitim uygulamalarının birleştirilmiş teknoloji kabul modeli ile araştırılması
}

\section{Investigation of compulsory distance education practices with integrated technology acceptance models during the coronavirus (COVID-19) pandemic}

1 Dr. Öğr. Üyesi, Kütahya Dumlupinar Üniversitesi, Türkiye,

\section{vasfi.kahya@dpu.edu.tr}

ORCID: 0000-0002-2154-5689

Başvuru/Submitted: 18/02/2021

Revizyon/Revised: 19/04/2021

Kabul/Accepted: 17/05/2021

Yayın/Online Published: 25/06/2021

Atıf/Citation: Kahya, V., Koronavirüs (COVID-19) salgını süresince zorunlu uzaktan eğitim uygulamalarının birleștirilmiş teknoloji kabul modeli ile araştırılması, bmij (2021) 9 (2): 737-750, doi: https://doi.org/10.15295/bmij.v9i2.1783
Vasfi Kahya ${ }^{1}$

Öz

Bu çalışma, 2020 yılında COVID-19'un neden olduğu küresel salgın sebebiyle eğitim kurumlarının zorunlu olarak geçtikleri uzaktan eğitim süreçlerinin öğrenciler tarafından kabulüne (acceptance) yönelik tutumları araştırmaktadır. Bu araştırma ile COVID-19 pandemisi döneminde zorunlu olarak geçilen uzaktan eğitim sisteminin öğrenciler tarafından nasıl algılandığını ve sistemin kabulüne sebep olan değişkenlerin Teknoloji Kabul Modeli ve Bilgi Sistemleri Başarı Modeli değişkenleri ile ortaya konulması amaçlanmıştır. 2019-2020 bahar dönemi uzaktan ders alan Kütahya Dumlupınar Üniversitesi ve Bilecik Şeyh Edebali Üniversitesi lisans ve ön lisans 377 öğrenciye anket uygulanmış, demografik soruların oluşturduğu bir bölüm ve değişkenlerin etkisini ölçmek amacıyla 5’li Likert tipi sorular yöneltilmiştir. Elde edilen bulgulara göre uzaktan eğitime erişmek için sahip olunması gereken teknolojik altyapı araçlarının sahiplik oranına bakıldığında öğrencilerin \%50'sinin sahip olduğu, \%50'sinin sahip olmadığı yönünde sonuca ulaşılmıştır. Ayrıca uzaktan eğitim platformunun kullanımını etkileyen bilgi kalitesi, sistem kalitesi ve algılanan fayda, kullanıcı memnuniyetini etkilediği sonucuna ulaşılmıştır. Kullanıcı memnuniyeti değişkeni ise kullanımı etkilemekte ve \%39 seviyesinde açıklamaktadır. Bu çalışma ile yüz yüze eğitime alternatif olarak kullanılan uzaktan eğitim platformunun öğrenci yönünde iyileştirilmesi, gerekli altyapı araçlarına sahip olunmasının sürecin daha başarılı yönetilmesi ve faydalı olması adına önemli olacağı düşünülmektedir.

Anahtar Kelimeler: Uzaktan Eğitim, COVID-19, Teknoloji Kabul Modeli, Bilgi Sistemleri Başarı Modeli, Birleştirilmiş Teknoloji Kabul Modeli

Jel Kodlari: D83, L15, I18

\begin{abstract}
This paper attempted to investigate the technology acceptance issues of the students caused by COVID-19, the global epidemic forcing educational institutions to shift towards distance education processes. This research aims to explain how the distance education system, which was compulsory during the COVID-19 pandemic period, was perceived by users and the variables that caused the acceptance or rejection of the system through the Technology Acceptance Model and The Information Systems Success Model variables. During the 2019-2020 spring semester, 377 undergraduate and graduate degree students from Kütahya Dumlupinar University and Bilecik Şeyh Edebali University took distance education courses 5-point Likert type questions were asked to measure the impact of demographic factors and main variables proposed by the questionnaire. According to the findings, it was seen that the universities owned only $50 \%$ of the required technological infrastructure tools. In addition, information quality, system quality and perceived benefit, which affect distance learning platforms, also affect the user satisfaction rates. The user satisfaction variable affects usage rate explaining $39 \%$ of the variable. It is asserted that the distance education platform is used as an alternative to face-to-face training, and that will be important for improving the user direction, having the necessary infrastructure tools, managing the process more successfully.
\end{abstract}

Keywords: Distance Learning, COVID-19, Technology Acceptance Model, Information Systems Success Model, İntegrated Technology Acceptance Models

Jel Codes: D83, L15, I18 


\section{Investigation of compulsory distance education practices with integrated technology acceptance models during the coronavirus (COVID-19) pandemic}

\section{Literature}

The coronavirus infection known as COVID-19, which soon has affected the whole world, was declared a pandemic by the World Health Organization, caused profound changes in human life in a short time and resulted in these changes becoming part of our long-term life. This research aimed to reveal how the distance education system, which was compulsory during the COVID-19 pandemic, was perceived by users. The variables that caused the acceptance or rejection of the system were revealed with the Technology Acceptance Model and Information Systems Success Model variables. Short-term schools and universities closed in Turkey on March 17, 2020, and then on March 23, 2020, the distance education model was adopted to continuing the education process (YÖK, 2020a). Although many universities have used panels where students and teachers interact, systemic problems have been experienced due to many users and the lack of infrastructure. Instead of live and real-time lessons, they continued with the courses from the recordings previously uploaded to the system. One side of the problems creates such infrastructure problems, while the other side creates different problems such as the acceptance of the system from the user perspective, the functionality of the learning panel, the ability of information and system quality. Considering that distance education will continue after the end of the pandemic, it is understood that such problems should be resolved (Wotto, 2020). On the other hand, distance education, which offers a very suitable environment for lifelong learning, is essential to eliminate its deficiencies in this respect (Chung et al., 2020). This study aims to shed light on the problems that universities have been experiencing today and in the future and take the necessary steps for lifelong education and benefit more from distance education, which seems to continue as part of our lives.

\section{Design and method}

Within this information framework, distance education students need to harmonise with the system they will use and adopt the necessary technology. Problems at the point of acceptance of new technology prevent the system's healthy functioning and cause the loss of a favourable environment for education. In this context, serious investigation of the learner (student) dimension of the distance education process and especially examining students' perceptions and responses to distance education models is necessary to increase the success of these systems. Many researchers have achieved better results in explaining behaviour with these new models, which have combined different theoretical models to achieve integrated models (Godoe and Johansen, 2012). In this study, the Technology Acceptance Model variables and Information Systems Success model variables are combined with Perceived Usefulness, System Quality, Information Quality, Usage Satisfaction and Usage variables. As system quality increases, usage satisfaction increases highly (Bailey and Pearson, 1983; Shibly, 2011). Another study investigating the distance learning satisfaction of system characteristics, the positive impact of information quality, system quality, and service quality on user satisfaction was observed on 250 Malaysian students (Ramayah and Lee, 2012). The universe of the present study is selected from Dumlupinar University and Şeyh Edebali University undergraduate and associate students. The prepared questionnaire reached every student who opened the courses to follow the courses loaded on the system. Of the 456 surveys sent to the participants, 391 were returned, 14 were excluded, and 377 survey forms were evaluated. As a result of a comprehensive literature review of the Technology Acceptance Model (TAM) variables and Delone and Mclean Information Systems Success (ISS) variables for the study, an integrated model was created by bringing together valid and reliable scales. It is indicated that integrated models are higher in description percentages (Taylor and Todd, 1995, Venkatesh et al., 2003; Shibly, 2011; Butler, 2015).

\section{Findings and discussion}

According to the data obtained within the scope of this study, the opinion that 'distance education is beneficial' is supported by approximately $50 \%$ of the respondents. Answering questions such as reaching regular internet access, having a personal computer and monitoring all courses are clustered around approximately 50\% favourable opinion. The remaining $50 \%$ are seen to answer questions negatively. Unfortunately, this clarifies that students are not sufficiently prepared for the critical distance education process regarding physical conditions. However, the other $50 \%$ of students who do not believe in the benefit of distance education should also be considered. The causes of this situation can be considered to be investigated in depth through a qualitative study. As a result of regression analyses, information quality, system quality, and perceived benefit variables significantly impact user satisfaction. The user satisfaction variable affects usage and explains it at $39 \%$. This study proposes that improving the distance education panel may be used as an alternative to face-to-face learning with more successful management of the process. The variable that has the most substantial impact on user satisfaction is system quality.

\section{Conclusion, recommendation and limitations}

In the current education interface, students experienced problems connecting to the system, slowdowns and interruptions due to excessive system demand in synchronous and asynchronous courses. The quality of information has an impact on user satisfaction in order to provide the necessary content and to meet the student's educational needs. Factors such as easy access to the system from anywhere, the possibility of connecting with mobile devices, the understandability of the system search side positively affect the perceived benefit. The necessity of distance education during the pandemic period can turn into an opportunity for developing technical infrastructures and being ready for technological developments and users to adopt and use distance education systems more effectively. In this study, data were collected from specific departments of two public universities, and the study's findings were reached in this way. It should be expressed as a constraint that the research should be carried out only in certain Dumlupinar and Şeyh Edebali Universities departments. A new study can be carried out by adding different variables on private or public universities that provide distance education and use different platforms, which will allow the distance education system, which enters our lives as the new normal and which we will often apply to during and after the pandemic period, to be more efficient. In addition, based on the findings obtained from this study, the reasons why users are dissatisfied with distance education can be investigated with a qualitative study. 


\section{Giriş}

Koronavirüs (COVID-19) olarak bilinen ve kısa zamanda dünyanın genelini etkisi altına alan enfeksiyon, Dünya Sağlık Örgütü tarafından pandemi olarak ilan edilmiş, insan yaşamında çok kısa sürede köklü değişikliklere sebep olmuş ve bu değişikliklerin uzun süreli hayatımızın bir parçası haline gelmiştir. Pandemi süreci eğitim kurumları açısından hem bir krize yol açmış hem de birçok gelişmeyi zorunlu hale getirmiştir. Bu süreçte eğitim kurumları, eğitimciler, öğrenciler ve velilerin yeni bir bakış açısı kazanmaları gerekmektedir (Bozkurt, 2020). Bu bağlamda öğrencilerin uzaktan eğitimin gerekliliğine ve faydalarına yönlendirilmesi gerekmektedir. Uzaktan eğitim çalışmalarında senkronize (eş zamanlı) öğrenme yöntemlerinin geliştirilmesinin eğitimde etkililiği artıracağı ifade edilmektedir (Daniel, 2020). Katılımcıların etkin bir şekilde eğitim içeriğinden faydalanması için interaktif ve yaratıcı yöntemlere de ihtiyaç duyulmaktadır (Keskin ve Özer Kaya, 2020). Bu süreçte eğitim materyallerinin geliştirilmesi ve öğrencilere etkin ve verimli şekilde ulaştırılması, ölçme ve değerlendirme yöntemlerinin objektif ve öğrencilere kolaylıkla anlayabilecekleri şekilde planlanması önemlidir. Pandemi sürecinin krizden ziyade fırsat olarak düşünülmesiyle birlikte uzaktan eğitimde ciddi ilerlemeler kaydedilmesi mümkün olabilir (Yılmaz İnce, Kabul, Diler, 2020).

Pandemi sürecinde başta sağllk, eğitim ve hizmet sektörleri olmak üzere birçok sektör derinden etkilenmiştir. Bu kapsamda eğitim kurumları dünya genelinde ve ülkemizde pandemiden etkilenerek çözüm yolları aranmaya başlanmıştır. Çözüm yolu olarak görülen uzaktan eğitime kurumlar açısından ve eğitimciler açısından ne kadar hazır olduğumuz tartışılmaktadır (Korkmaz ve Toraman, 2020). COVID-19 pandemisinin görüldüğü tüm ülkeler öncelikli olarak eğitimin devam ettirilmesi çabasına girmiştir.

Türkiye'de 17 Mart 2020'de kısa süreli okul ve üniversiteler kapanmış daha sonra 23 Mart 2020'de uzaktan eğitim modeline geçilerek eğitimin devam etmesi sağlanmıştır (YÖK, 2020a). Bu noktadan sonra üniversitelerin altyapı ve uzaktan eğitim vermek için gerekli olan sistemlerin araştırılmasına geçilmiş Anadolu Üniversitesi, İstanbul ve Atatürk Üniversitesi gibi daha önce altyapısı hazır olan uygulamalar incelenmiştir. Kısa sürede birçok üniversite uzaktan eğitim altyapısını hazırlayarak eğitim vermeye başlamıştır. Nitekim YÖK'ün 23 Mart'ta yapmış olduğu açıklamada 123 üniversitenin uzaktan eğitim vermeye hazır olduğu ifade edilmiştir (YÖK, 2020b). Birçok üniversite öğrenci ve öğretmenin karşılıklı etkileşim içinde olduğu bir eğitim modelinin benimsendiği paneller kullanmış olmasına rağmen kullanıcı sayısının çokluğu ve altyapının yeterli gelmemesi sonucu sistemsel sorunlar yaşanmış, canlı dersler yerine daha önce sisteme yüklenen kayıttan derslerle devam edilmiştir. Sorunların bir tarafını bu gibi altyapı problemleri oluştururken diğer tarafını da kullanıcı açısından sistemin kabulü, eğitim platformunun işlevselliği, bilgi ve sistem kalitesinin yeterliliği farklı bir sorun oluşturmaktadır. Pandeminin sona ermesinden sonra da uzaktan eğitimin devam edeceği düşünüldüğünde bu gibi sorunların çözümlenmesi gerektiği anlaşılmaktadır (Wotto, 2020). Diğer taraftan hayat boyu öğrenme için oldukça uygun bir ortam sunan uzaktan eğitim bu açıdan da eksikliklerinin giderilmesi önemli olmaktadır (Chung, Subramaniam, Dass, 2020).

Pandemi sürecinde yüksek eğitimin geleceğine ilişkin çok sayıda çalışma yapıldığı görülmektedir. Bu çalışmalara genel bir çerçeveden bakıldığında; Oranburg (2020), Dhawan (2020) tarafından uzaktan eğitim verenlerin hızlı ve kolay stratejiler geliştirilmesi ele alındığını; Bozkurt (2020), Keskin ve Özer Kaya (2020), tarafından pandemi süreci ve sonrası eğitime yönelik değerlendirmelerin yapıldığını; Telli Yamamoto ve Altun (2020) tarafından çevrimiçi eğitimin yükselişi ile ilgili çalışmalar yapıldı̆̆ını ve son olarak Pal ve Vanijja (2020) ve Yılmaz İnce vd. (2020) tarafından uzaktan eğitim için kullanılan uygulamaların algılanan faydası araştırıldığı görülmektedir. Bu çalışmaların bir kısmı uzaktan eğitimde sistem gereklilikleri, sistem yeterliliği ile ilgiliyken; kullanıcı deneyimi, teknoloji kabulü ve sürecin öğrenme etkinliği üzerinde durulan çalışmalar olduğu görülmektedir. Bu çalışmanın amacı, COVID-19 pandemi sürecinde uzaktan verilmeye başlanan eğitimin öğrenciler tarafından nasıl algılandığını birleştirilmiş teknoloji kabul modeli ile keşfetmek ve öğrencilerin gerekli altyapıya sahip olup olmadıklarını ortaya koymak amacıyla yapılmaktadır. Uzaktan eğitim bilindiği üzere bir takım elektronik cihazlar üzerinden yürütülüyor olması hem ders veren hem de alan açısından gerekli alt yapıyı oluşturan cihazlara sahip olmayı gerektirmektedir. Bu çalışma ile üniversitelerin bugün ve gelecekte yaşadıkları ve yaşayabilecekleri sorunlara ışık tutmak hem hayat boyu eğitim için gerekli adımların atılmasına hem de hayatımızın bir parçası olarak devam edecek gibi görünen uzaktan eğitimden daha fazla fayda sağlayacağı çıkarımlara ulaşılacağı düşünülmektedir.

\section{Uzaktan eğitim}

Literatürde uzaktan eğitim kavramı tarihte ilk olarak 1892 y1lında Wisconsin Üniversitesi'nin yayınlamış olduğu eğitim kataloğunda geçmektedir. Yüz yüze derse katılma imkânı olmayan kişiler 
için eğitime erişme ihtiyacına karşılık verebilmek amacıyla ortaya çıkmıştır (Harting ve Erthal, 2005). Bilişim teknolojilerinin hızla gelişmesi uzaktan etkileşim kabiliyetinin daha interaktif hale dönüşmesi ile uzaktan eğitim yeni bir boyut kazanmış geleneksel eğitim şekillerinde birtakım değişiklikler ve öğrenme süreçlerinde yenilikleri beraberinde getirmiştir. Bilgisayarın bir eğitim aracı olarak kullanılmaya başlanması ile yazılı ve elektronik medyanın dağıtılması imkânına kavuşulmuştur (Moore, 1990). Dolayısıyla uzaktan eğitim; fırsat eşitsizliğine çözüm getiren, isteyen herkese yaşam boyu eğitim sağlayan ve bunların yanı sıra eğitimin bir dizi bireysel ve toplumsal amaçlarının gerçekleştirilmesine katkıda bulunabilen, eğitim teknolojilerinden yararlanmaya ve daha çok kendi kendine öğrenmeye de imkân veren bir disiplin olarak ifade edilmektedir (Kaya, Erden, Çakır, Bağısakçı, 2004:166). Uzaktan eğitim, gelişen teknolojik imkânların sunmuş olduğu alt yapı ve cihazlarla verilen eğitimin zamandan ve mekândan bağımsız öğrencilere ulaşmasını sağlayan sistemler bütünüdür (Lehman ve Russell, 2006; Ağaoğlu, İmer, Kurubacak, 2002). Bir başka tanımda ise "uzaktan eğitim, farklı mekanlarda bulunan öğrenci, öğretmen ve öğretim materyallerinin iletişim teknolojileri aracılığı ile bir araya getirildiği kurumsal bir eğitim faaliyetidir" denilmiştir. (Gülbahar, 2012:2).

Nipper (1989) uzaktan eğitim sürecini üç döneme ayırmıştır. Birinci dönem, posta yolu ile öğrencilerle iletişimin kurulduğu karşılıklı yazışma esasına dayalı öğrenme biçimini ifade etmektedir. Ülkemizde bu şekilde eğitime örnek olması açısından ilk örnekleri 1974 yılında başlayan Deneme Yüksek Öğretmen Okulu uzaktan öğretmen yetiştirme süreçleri örnek gösterilebilir (Gelişli, 2015:318). İkinci dönemde, dijital teknolojinin biraz daha gelişmesi ile hayatımıza giren sesli ve görüntülü iletişim araçları ile eğitimin verilmesi esas alınmıştır. Televizyon ve radyo yayınları ile yapılan bu eğitimler ilk döneme göre daha fazla görsel ve işitsel imkân sunmaktadır. Yine ülkemizde bu sürece örnek olarak açı öğretim ders modelleri gösterilebilir. İlk iki dönemin temeldeki amacı eğitim materyallerinin üretim ve dağıtımı olarak söylenebilir. Üçüncü dönem ise ilk iki döneme göre farklılık göstermektedir. Öğretmen ve öğrenci arasında çift yönlü bir iletişimin ve etkileşimin olması yönüyle ilk iki kuşak öğrenme şekillerinden farklılık göstermektedir. Bilgisayar destekli iletişim ve video konferanslar aracılığı ile elde edilen etkileşim bir süreç olarak değerlendirildiğinde iletişim temelli bir yapı ön plana çıkmaktadır (Jones, 1996:139).

Üçüncü dönem uzaktan öğrenme modeli ile öğretmen ve öğrenci arasında kurulan bağ yeni boyut kazanmış küresel eğitim ve iletişim imkânını beraberinde getirmiştir. İletişim teknolojilerinin yoğun kullanıldığı bu dönemde öğretmen ve öğrenci bir sınıf ortamındaymış gibi bir araya gelerek sınıf ortamındaki havanın yakalanması senkron diyalog geliştirilebilmesi ya da asenkron bir şekilde daha sonra tekrar tekrar izleyebilme imkanına sahip olması açısından uzaktan eğitimi farklı bir noktaya taşımıştır.

Bu bilgiler çerçevesinde uzaktan eğitim öğrencilerinin kullanacakları sistem ile uyum içinde olmaları, gereken teknolojiyi benimsemeleri büyük önem taşımaktadır. Yeni teknolojinin kabulü noktasında çıkan sorunlar sistemin sağlıklı işlemesine engel olurken eğitim için elverişli ortamın kaybolmasına sebep olmaktadır. Bu bağlamda uzaktan eğitim sürecinin öğrenci boyutunun da ciddi şekilde araştırılması ve özellikle öğrencilerin uzaktan eğitim modellerine karşı algılama ve tepkilerinin incelenmesi bu sistemlerin başarısını artırmak için gereklidir. Bu bağlamda uzaktan eğitiminde dahil olduğu teknolojik gelişmelere karşı ortaya çıkan tepkilerin araştırılması amacıyla çok sayıda teknoloji kabul modeli ortaya atılmış ve sistemin kabulü araştırılmıştır (King ve He, 2006; Park, 2009).

\section{Teknoloji kabul modeli}

Bilişim sistemleri alanında 1980'li yıllarda araştırmacıların en çok merak ettiği konu bireyin bilgisayar kullanımını etkileyen kabul (acceptance) sebeplerini anlamak olmuştur (Davis, Bagozzi, Warshaw, 1989:982). Kullanıcıların neden bilgisayar kullanımına karşı direnç gösterdiğini, değişikliklere nasıl cevap vereceklerini ve bunlar arasındaki ilişkiyi anlamaya çalışmak giderek önemi artan bir konu haline gelmiştir. Bu nedenle araştırmacılar bir sistemin neden kabul edilemez olduğuna yönelik bir tanımlama yapabilmeli ve düzeltici önlemler konusunda bir öneri sunması gerekliliğinin bilincinde olmuşlardır (Davis vd., 1989:985-986).

Teknoloji kabul modeli (TKM) az değişken ile nispeten güçlü açıklayıcılığı sayesinde kısa zamanda ilgi gören ve çok sayıda çalışmaya konu olan bir model haline gelmiştir. Algılanan fayda ve algılanan kullanım kolaylığı değişkeni ile kullanıcı niyeti açıklanmaya çalışılmıştır. TKM, yeni kullanıcılar tarafından kabul derecesine yönelen, kullanıcı davranışını öngörmeye çalışan açıklayıcılığı güçlü bir model olmuştur (Erdem, 2011:24). TKM, önemli bir sosyo-psikolojik teori olan Sebepli Faaliyetler Teorisi'nden (SFT) uyarlanmış ve zaman içinde yapılan birçok çalışma, teorinin kuvvetli ve tahmin gücü yüksek bir teori olduğunu ortaya koymuştur (Wang, 2002). Pek çok akademik araştırma ve çalışmaya rağmen kullanıcı açısından teknoloji kabul sürecinin nasıl işlediği, tam olarak anlaşılabilmiş 
değildir. Fakat kullanıcı açısından, özünde teknoloji bulunan bir uygulamanın benimsenmesi ya da benimsenmemesinin, son tahlilde o uygulamanın kabul ve kullanımıla ilişkili olduğu bilinmektedir (Turan ve Özgen, 2009). Araştırmacılar kullanıcı kabulünü anlamak için yeni modeller üretmiş ve modelin açıklama gücünü arttırmaya çalışmışlardır. Pek çok araştırmacı ise farklı teorik modelleri birleştirerek entegre modeller elde etmiş bu yeni modellerle davranışı açıklayabilme konusunda daha iyi sonuçlara ulaşmışır (Godoe ve Johansen, 2012). TKM, kullanıcıların bilgi teknolojisini kullanmadaki davranışını anlama ve açıklamada çok faydalı bir model olarak görülmesine rağmen, TKM'nin insani ve sosyal faktörleri içermemesi çok defa eleştirilen bir konu olmuştur (Lucas ve Spitler, 2000; Legris vd, 2003; Sun ve Zhang 2006). Bu yüzden daha iyi sonuçlar almak için TKM'nin başka modellerle birleştirilmesi gerektiği fikri sıklıkla ortaya atılmıştır (Park vd., 2015). Birleştirilmiş modellere çok sayıda örnek göstermek mümkündür. Taylor ve Todd (1995)'un yapmış olduğu deneyimli ve deneyimsiz kullanıcıların davranışlarını ölçmek için TKM ve Planlı Davranış Teorisi (PDT) modelleri birleştirilmiştir. Zaied (2012) ise TKM ve BS Başarı Modeli değişkenlerini birleştirerek entegre bir model elde etmiş, kamu alanında yeni teknolojilerin kullanımına olan yatkınlığı ölçmüştür. Amaro ve Duarte (2015) TKM, PDT ve SFT modellerini birleştirerek online seyahat tercihlerini etkileyen unsurları keşfetmeye çalışmıştır.

DeLone ve McLean Bilgi Sistemleri Başarı Modeli (BS Başarı Modeli) ise sistem ve insani faktörleri içine alan değişkenleri ile birçok entegre modele katkı yapmaktadır. Bilgi sistemleri içinde bulunan bilgi kalitesi, sistem kalitesi, memnuniyet ve kullanım değişkenleri ile TKM değişkenleri ile birleşmesi yukarıda da ifade edildiği gibi modellerde açıklama düzeyini olumlu etkilediği görülmüştür.

Bu çalışmada daha önce de kullanılan entegre modellere ek olarak TKM değişkenleri temel alınarak BS Başarı Modeli değişkenleri bir model üzerinde birleştirilmiş, kullanım memnuniyetine bağlı olarak ortaya çıkan kullanımın nasıl algılandığının tahmin edildiği bir model ortaya çıkarılmıştır.

\section{Delone ve Mclean bilgi sistemleri başarı modeli}

Birçok araştırmacı bilgi sistemlerini etkileyen faktörleri bulmaya yönelik çalışmalar yürütmüşler, bilgi sistemlerinin etkinliğinin ölçülmesi açısından bu değişkenlerin keşfini önemli bulmuşlardır. Bu çalışmalar neticesinde Delone ve Mclean tarafından 1981 ve 1987 yılları arasında yayınlanan makaleler gözden geçirilerek bilgi sistemlerinin başarısını açılamak üzere bir model geliştirilmiştir (Delone, Mclean, 1992). Araştırmacıların bu yeni modelden beklentileri bilişim sistemlerinin kullanımı ve elde edilen faydanın açıklanabilmesi olmuştur. (Ashill ve Jobber, 1999:519). DeLone ve McLean Bilgi Sistemleri Başarı Modeli birbiri ile bağlantılı 6 farklı değişkenden oluşmaktadır. Sistem kalitesi, bilgi kalitesi, sistem kullanımı ve memnuniyeti, bireysel ve örgütsel etkiler modelde yer almaktadır.

\section{Uzaktan eğitim ve kabul teorilerine ilişkin literatür taraması}

Değişimin sürekli olarak yaşandığı dünyamızda alışık olduğumuz birçok uygulamanın kısa zamanda yerini bir başka uygulamaya bıraktığını görebiliriz. Değişim o kadar hızlı bir şekilde gerçekleşiyor ki çoğu zaman kullanıcılar yeni teknolojiyi kullanıp kullanmama gibi bir seçim hakkı tanınmadı̆̆ı gibi yeni teknolojiyi kullanma mecburiyeti ile karşımıza çıkabilmektedir. Bu hızlı değişim sürecinde bireylerin her yeni oluşuma uyum sağlaması öncelikli bir konu haline gelmiş araştırmacılarda bu değişime direnç oluşturan faktörleri keşfetmek için farklı modeller önermişlerdir. Eğitim süreci de teknolojideki bu değişimi yavaş yavaş gündemine almış uyum sağlamak adına adımlar atılmaya başlanmıştır. Fakat pandemi ile gelen ani değişim talebi birçok kurum için zorlu geçiş süreçlerinin yaşanmasına sebep olmuştur. Birçok eğitim kurumunun bu sürece hazır olmaması, eğitim kurumlarının uzaktan eğitime bakış açılarını, öğrenci ve öğretmen açısından değerlendirilmesini, kullanılan web tabanlı uygulamaların verimliliğini ve önündeki engellerin araştırıldığı birçok çalışmaya konu olmasına sebep olmuştur. Bu alanda yapılan bazı çalışmalara aşağıda yer verilmektedir.

Negüs'ün (2016) yapmış olduğu lisans öğrencilerinin kabulüne ilişkin tutumlarını araştırdığı çalışmada bireyin teknolojiye karşı tutumları ve mevcut teknolojiyi kabulünün sistemin icrası açısından kritik öneme sahip olduğu sonucuna ulaşılmıştır. Çelik ve Sökmen'in (2018) yaptığı çalışmada ise uzaktan eğitime devam etme niyeti araştırılmış, özellikle kullanıcı memnuniyetinin devam etme niyeti üzerinde anlamlı etkisi olduğu sonucuna ulaşılmıştır. Bununla birlikte bilgi kalitesinin kullanıcıların memnuniyetleri üzerinde anlamlı bir etkiye sahip olmadığı tespit edilmiştir. Yiğit vd., (2010) öğretmen ve öğrencilerin uzaktan eğitime bakış açılarının araştırdığı çalışmada esnek olması, iş ve sosyal hayatı olumsuz etkilememesi, araştırma ve kavrama becerilerini olumlu etkilemesi sonuçlarına ulaşılmıştır. Öğretim elemanları açısından ise uzaktan eğitimin tek başına yeterli olmadığı sonucuna ulaşılmıştır. Oranburg (2020), COVID-19 sürecinde eğitim verenlere hızlı ve kolay uyum stratejilerinden bahsettiği çalışmada, uzaktan eğitim sürecinde kullanılması durumunda eğitim kalitesini arttıracak uygulamalardan bahsetmektedir. Telli Yamamoto ve Altun (2020), online eğitimin önlenemeyen 
yükselişini araştırmışlar, kriz sonrası da ana akım öğrenme haline dönüşmesi konusu ele alınmıştır. Keskin ve Özer Kaya (2020), web tabanlı uzaktan eğitim faaliyetlerinin geri bildirimlerinin değerlendirildiği çalışmada, öğrencilerin \%84,4'ü web tabanlı uzaktan eğitimin yüz yüze eğitim kadar etkili olmadığını, \%45,7'si bunun yüz yüze eğitime alternatif olduğunu belirtmiştir. Öğrenciler öğretim elemanlarıyla rahatça iletişim kuramadıklarını $(\% 49,9)$, web tabanlı eğitimin kendi hızlarında öğrenmelerine olanak sağladığını (\%60,7), ancak öğrenilenin çabuk unutulduğunu (\%74,6) ve eğitimler sırasında teknik sorunlar yaşadığı $(\% 53,9)$ sonuçlarına ulaşılmıştır. Pal ve Vanijja (2020), Microsoft Teams platformu üzerinden verilen uzaktan eğitimin başarısını etkileyen faktörleri araştırmış, TKM ve BS Başarı Modeli değişkenlerinden faydalanmıştır. Algılanan kullanım kolaylığının sistem kullanımında en önemli etken olduğu sonucuna varılmıştır. Rizun ve Strzelecki (2020) ve Pho vd., (2020), öğrencilerin uzaktan eğitimde sistem kabulünü kolaylaştıran etkenlerin araştırıldığı çalışmada eğlence, öz yeterlilik, algılanan fayda ve algılanan kullanım kolaylığı değişkenlerinin memnuniyeti etkilediği görülmüştür.

\section{Araştırma modeli ve hipotezleri}

Bu araştırma, COVID-19 pandemisi sürecinde Kütahya Dumlupınar Üniversitesi ve Bilecik Şeyh Edebali Üniversitesi lisans ve ön lisans eğitimi alan öğrencilerin görüşleri alınarak elde edilen bilgilerin neticesinde zorunlu uzaktan eğitimin genişletilmiş TKM ve BS Başarı modeli ile öğrenciler tarafından kabul (acceptance) unsurlarının değerlendirilmesidir. Bu çalışmada uzaktan eğitim öğrencilerinin, uzaktan eğitim sisteminin başarısına yönelik olası belirleyiciler ve kısıtlar çerçevesinde oluşturulan bir model test edilmektedir. Modelin temel varsayımı sistem kullanımı (başarı); kullanıcı memnuniyetini oluşturan sistem kalitesi, bilgi kalitesi ve algılanan fayda fonksiyonları tarafından belirlendiğidir.

\section{Algılanan fayda}

Algılanan Fayda, kullanııların teknoloji kullanımı sonucunda yaptıkları işteki performans artışları ile ilgili sahip oldukları olumlu ya da olumsuz düşüncelerdir (Davis, 1989:320). Algılanan fayda; kullanım niyeti, kullanıcı tatmini ve kullanım memnuniyetinin en önemli açıklayıcılarından biri olduğu vurgulanmaktadır (Bhattacherjee, 2001; Plouffe vd., 2006; Shibly, 2011). Seddon (1997) tarafından bilişim sistemleri başarı modeline göre algılanan faydanın kullanıcı memnuniyetini açıkladığı ifade edilmiştir. Devaraj vd. (2002) tarafından e-ticaret ile ilgili çalışmada algılanan faydanın müşteri memnuniyetini önemli ölçüde etkilediği belirtilmektedir. Liao vd. (2007)'ne göre kullanım memnuniyeti ile algılanan faydanın açıklama düzeyine önemli katkısı olduğu ifade edilmektedir. Bu kapsamda geliştirilen hipotez aşağıdaki gibidir:

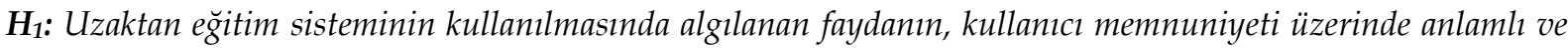
pozitif bir etkisi vardır.

\section{Sistem kalitesi}

Sistem kalitesi, bilişim sistemlerinin gerekli bilgiyi gerekli kalitede sunabilme kabiliyeti olarak açıklanmaktadır. Sistem kalitesinin iyi olması aynı zamanda donanım ve yazılım arasında ilişkinin de iyi olması anlamına gelmektedir. Sistem kalitesi arttıkça kullanım memnuniyeti o derece artması beklenmektedir (Bailey ve Pearson, 1983; Shibly, 2011). Kullanım kolaylığı, fonksiyonel oluşu, veri işleyebilme kabiliyeti, güvenilirlik sistem kalitesi için önemli etkenlerdir. Bu kapsamda oluşturulan hipotezimiz:

$\mathrm{H}_{2}$ : Sistem kalitesi, uzaktan eğitim sisteminin kullanıcı memnuniyeti üzerinde anlamlı ve pozitif bir etkiye sahiptir.

\section{Bilgi kalitesi}

Bilgi kalitesi, sistemin ürettiği bilginin çıktı kalitesini ölçmektedir. Bilgi sisteminin ürettiği bilginin tamlık, doğruluk, erişilebilirlik, zamanlılık, tutarlılık ve anlaşılabilirlik gibi özelliklere sahip olması gerekmektedir (Bailey ve Pearson, 1983; DeLone ve McLean, 1992). Delone ve McLean (1992), yapmış oldukları çalışmada bilgi kalitesinin kullanıcı memnuniyeti ve kullanım başarısını etkilemesi açısından önemli etkiye sahip olduğu bulunmuştur. Sistem karakteristiğinin uzaktan öğrenme memnuniyetinin araştırıldığı çalışmada 250 Malezyalı öğrenci üzerinde araştırma yapılmış bilgi kalitesi, sistem kalitesi ve hizmet kalitesinin kullanıcı memnuniyeti üzerinde olumlu etkisi görülmüştür (Ramayah ve Lee, 2012). Bu kapsamda oluşturulan hipotezimiz:

$\mathrm{H}_{3}$ : Bilgi kalitesi, uzaktan eğitim sisteminin kullanıcı memnuniyeti üzerinde anlamlı ve pozitif bir etkiye sahiptir. 


\section{Kullanıcı memnuniyeti}

Bhattacherjee (2001) tarafından yapılan bilgi sistemlerini anlamaya yönelik çalışmada algılanan faydanın kullanıcı memnuniyetini önemli derecede etkilediği tespit edilmiştir. Lin (2007), çevrimiçi öğrenme başarısını etkileyen faktörleri belirlemeye yönelik yaptığı çalışmada sistem kalitesi, bilgi kalitesi ve hizmet kalitesinin kullanıcı memnuniyeti ve kullanım üzerinde etkisi olduğunu bulmuştur. Satın alma niyetini ölçen çeşitli çalışmalarda kullanıcı memnuniyetinin satın alma niyeti üzerinde olumlu etkiye sahip olduğu ifade edilmiştir (Bitner, 1990). Bu kapsamda oluşturulan hipotezimiz:

$\mathrm{H}_{4}$ : Kullanıcı memnuniyeti, kullanım başarısı üzerinde anlaml ve pozitif bir etkiye sahiptir.

Hipotezler kapsamında oluşturulan modelimiz aşağıdaki gibidir;

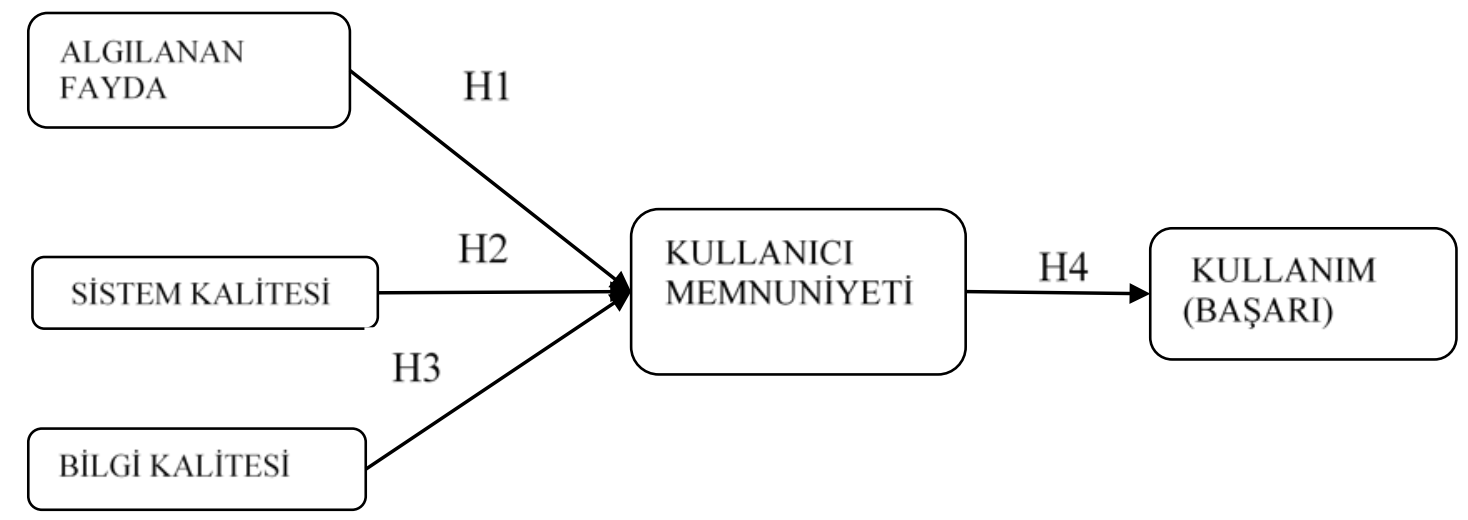

Şekil 1: Araştırma Modeli

\section{Araştırmanın yöntemi}

Bu çalışma, 2020 yılında COVID-19'un neden olduğu küresel salgın sebebiyle eğitim kurumlarının zorunlu uzaktan eğitim süreçlerinin öğrencilerin sistem kabulüne yönelik tutumlarını araştırmaktadır. $\mathrm{Bu}$ araştırma ile COVID-19 pandemisi döneminde zorunlu olarak geçilen uzaktan eğitim sisteminin öğrenciler tarafından nasıl algılandığını ve sistemin kabul veya reddine sebep olan değişkenlerin TKM ve BS Başarı Modeli değişkenleri ile ortaya konulması amaçlanmıştır. Araştırmanın evrenini Dumlupınar Üniversitesi ve Şeyh Edebali Üniversitesi lisans ve ön lisans öğrencileri oluşturmaktadır. Hazırlanan anket formu öğrencilerin dersleri izlediği sistem üzerine yüklenmiş ders izlemek için açan her öğrenciye ulaşmıştır. 456 anket formu görüntülenmiş 377 adet geri dönüş olmuştur. Teknoloji kabulünü araştıran birçok çalışma, bilgi teknolojilerinin kullanımını etkileyen faktörleri bulmak için farklı teorik modelleri birleştirerek ya da değişkenler ekleyerek entegre modeller oluşturma yoluna gitmiştir. Entegre modellerin açıklama yüzdeleri açısından daha yüksek olduğu belirtilmektedir (Taylor ve Todd, 1995, Venkatesh vd., 2003; Shibly, 2011; Kahya, 2015). Bu çalışma için de TKM değişkenleri ve BS Başarı Modeli değişkenleri kapsamlı bir literatür taraması sonucunda geçerliliğgi ve güvenilirliği önceden tespit edilmiş ölçeklerden bir araya getirilerek entegre bir model oluşturulmuştur (Efiloğlu Kurt, 2015; Çelik ve Sökmen, 2018; Pal ve Vanija, 2020). Yapılan araştırmalar neticesinde 39 ifadelik bir anket formu oluşturulmuş ilk 6 ifade demografik değişkenlere yönelik diğer 33 ifade ise TKM ve Delone ve McLean Bilgi Sistemleri Başarı (BS) ölçeğinden oluşturulmuştur. Araştırma soruları öğrencilere 20192020 Bahar Dönemi sonunda yöneltilmiş ve veriler bu dönem içinde toplanmıştır.

Bu kapsamda anketi oluşturulan ölçeklerin, sistem kalitesini ölçmek için Wixon ve Todd (2005) ve Huang vd. (2004) tarafından geliştirilen yedi maddelik ölçek kullanılmıştır. Bilgi kalitesini ölçmek için Bailey ve Person (1983) bilgi kalitesi içeriğini ölçen yedi maddelik ölçeği kullanılmıştır. Algıllanan fayda boyutu, Sun ve Zhang'ın geliştirdiği altı maddelik ölçeği ile ölçülmüştür. Kullanım memnuniyeti ile ilgili soruların oluşturulmasında Seddon ve Yip (1992) ile Sun ve Zhang (2006) tarafından geliştirilen altı maddelik sorulardan faydalanılmıştır.

Kullanıcı davranışını ölçen birçok teorinin birbirine üstünlüğü kesin olarak ifade edilememiştir. Yapılan çok sayıda çalışmada farklı teorik modellerin (teknoloji kabul modeli, sebepli faaliyetler teorisi, planlı davranış teorisi) karşılaştırılmasında hiçbir modelin kullanıcı davranışını açıklama konusunda diğerine karşı kesin ve daimî bir üstünlük açıklayamadığı görülmektedir ((Taylor ve Todd, 1995b; Mathieson, 1991; Plouffe vd., 2001; Hung ve Chang, 2005). Bu çalışmalarda önemle vurgulanan husus ise yapılan çalışmanın türü ve niteliğinin modeller arası üstünlük durumunu belirlemede önemli olduğudur. 
Sistem kullanımının zorunlu olması ya da olmaması gibi etkenler, modeller arası üstünlükleri belirlemektedir.

\section{Araştırmanın bulguları}

Araştırma verileri IBM SPSS 24 ile değerlendirmeye tabi tutulmuş, verilerin değerlendirilmesi için güvenilirlik, faktör, korelasyon ve regresyon analizleri yapılmıştır.

\section{Frekans dağılımları}

COVID-19 pandemi sürecinde uzaktan eğitim alan öğrencilere ait demografik bilgiler Tablo 1'de verilmektedir.

Tablo 1: Frekans Dağılımları

\begin{tabular}{r|ll} 
Cinsiyet & Frekans & Yüzde \\
Kadın & 238 & 63,2 \\
Erkek & 139 & 36,8 \\
Okuduğunuz Bölüm & & \\
İnsan Kaynakları & 118 & 31,3 \\
Çocuk Gelişimi & 114 & 30,2 \\
Halkla İlişkiler ve Tanıtım & 80 & 21,3 \\
Yerel Yönetimler & 65 & 17,2 \\
musunuz? & & \\
Evet & 168 & 44,5 \\
Hayır & 209 & 55,5 \\
Ezaktan eğitimin faydalı olduğunu düsünüor & & \\
Hayır & 177 & 53 \\
Kişisel bilgisayarınız var mı? & & 47 \\
Evet & 192 & \\
Hayır & 185 & 51 \\
Evet & 187 & 49 \\
Hayır & 190 & 49,7 \\
Ders videolarının tamamını izliyor musunuz? & & 50,3 \\
Evet olarak yeterli internete ulaşabiliyor musunuz? & 136 & \\
Hayır & 241 & 63,9
\end{tabular}

Tablo 1'de görüldüğü üzere katılımcıların cinsiyetlerine göre incelendiğinde kadın katılımcıların çoğunlukta olduğu görülmektedir (\%63). Kayıtlı olunan bölümün sorulduğu soruda ise yoğunluğun İnsan Kaynakları $(\% 31,3)$ ve Çocuk Gelişimi $(\% 30,2)$ bölümlerinde olduğu görülmektedir. Uzaktan eğitimin faydalı olup olmadığı şeklinde yöneltilen soruya \%55,5 ile faydalı olmadığı yönünde bir cevap alınmıştır. Bu da dikkate alınması gereken önemli bir bulgudur. Dersleri izleyebilmek için gerekli internet hizmetine yeterli ve ihtiyacı karşılayacak düzeyde ulaşılıp ulaşılamadığı sorusuna ise yarı yarıya yakın bir cevap alınmıştır. Katılımcıların \%53'ü yeterli ve düzenli internete ulaşabilirken \%47'si ise ulaşamadığını ifade etmektedir. Uzaktan eğitim için olmazsa olmazlardan biri olan bilgisayara sahip olma oranında ise \%51'i sahip olduğunu ifade etmektedir. Kütahya Dumlupınar ve Bilecik Şeyh Edebali Üniversitelerinde derslerin takibi zorunlu olmamakla birlikte sisteme giriş yapan ve dersi açan her öğrenci dersin tamamını dinlememiş bile olsa dersi izlemiş görünmektedir. Bu açıdan katılımcılara yöneltilen ders videolarının tamamını izliyor musunuz sorusuna ise takip eden öğrencilerin yarısının izlediğini diğer yarısının tamamını izlemeden dersten ayrıldığı görülmektedir. Uzaktan eğitimle birlikte uygulamada karşılaşılan problemlerden birisi de ölçme ve değerlendirmenin nasıl yapılacağı hususudur. Sınavların ödev veya sınav şeklinde yapılması ve özellikle 2019-2020 bahar döneminde ders verenler tarafından genellikle ödev verilerek sınav değerlendirme yapılacak olması öğrencilerin dersleri takibi konusunda rehavete sebep olmaktadır. Sınavların ödev şeklinde yapılacağı kararından sonra öğrencilerin dersi takip etme ile ilgili vermiş oldukları cevaplar ise \%64 oranında herhangi bir değişiklik olmadığı yönündedir. 


\section{Faktör ve güvenilirlik analizleri}

Anket yolu ile elde edilen verilere faktör analizi öncesi güvenilirlik testi yapılmıştır. Güvenilirlik testleri sonucu Cronbachs' Alpha = 0.892 çıkmış ve 0,60' 1n üzerinde olduğu için yeterli görülmüştür. Faktör analizine uygunluğunu test etmek için Bartlett Sınaması ve Kaiser - Mayer - Olkin (KMO) sonuçlarına bakılmıştır. Bartlett Değeri = 3649,147, p = 0,000 olarak hesaplanmıştır. KMO değeri = 0,711; p =0.000 olarak hesaplanmıştır. Sosyal bilimler alanındaki araştırmalarda genellikle KMO değerinin 0,60'tan büyük olması örneklem büyüklügünün yeterli olduğunu göstermektedir. Elde edilen bu bulgular, verilerin faktör analizi için uygun olduğunu göstermektedir. Araştırma ölçeklerinin daha önce çalışmalarda kullanılan ve teknoloji kabul modeli literatüründe birçok çalışmada kullanılmış güvenilirlik ve geçerliliği ispatlanmıştır. Araştırmada yer alan 33 ifade doğrulayıcı faktör analizine (DFA) tabi tutulmuştur. Eigenvalues değerinin 1'den büyük olmasına dikkat edilmiştir. Yapılan analizde faktör yüklerinin 0,45 ve üzeri olacak şekilde dağılım yapılması sağlanmış ve buna göre ifadelerin 5 faktörde toplandı̆̆ı görülmüştür.

Tablo 2: Faktör Analizi Sonuçları

\begin{tabular}{|l|c|c|}
\hline Sorular & Faktör Dağılımı & Açıklanan Varyans \\
\hline Algılanan Fayda (AF) & $0,512-0,744$ & 17,616 \\
\hline Bilgi Kalitesi (BK) & $0,48-0,852$ & 12,562 \\
\hline Sistem Kalitesi (SK) & $0,612-0,689$ & 14,514 \\
\hline Kullanıcı Memnuniyeti (KM) & $0,523-0,754$ & 11,117 \\
\hline Kullanım(K) & $0,521-0,811$ & 16,985 \\
\hline KMO değeri: 0,711 & Toplam: 72,794 \\
\hline Bartlett's Sphericity: $3649,147 \mathrm{p}=0,000$ & \\
\hline
\end{tabular}

Bu çerçevede yapılan açıklayıcı faktör analizinde Varimax rotasyon metodu uygulanmıştır. Elde edilen tabloya göre faktör dağılımlarının literatüre uygun olarak dağıldı̆̆ı görülmektedir.

\section{Korelasyon analizi sonuçları}

Tablo 3: Değişkenler Arası Korelasyon Tablosu

\begin{tabular}{|l|l|l|l|l|l|l|}
\hline Değişkenler & Ort. & AF & BK & SK & KM & K \\
\hline Algılanan Fayda (AF) & 4,08 & 1 & & & & \\
\hline Bilgi Kalitesi (BK) & 4,11 & $0,702^{* *}$ & 1 & & & \\
\hline Sistem Kalitesi (SK) & 3,96 & $0,749^{* *}$ & $0,792^{* *}$ & 1 & & \\
\hline Kullanıcı Memnuniyeti (KM) & 3,13 & $0,689^{* *}$ & $0,695^{* *}$ & $0,758^{* *}$ & 1 & \\
\hline Kullanım (K) & 3,26 & $0,610^{* *}$ & $0,547^{* *}$ & $0,609^{* *}$ & 0,549 & 1 \\
\hline${ }^{* *} \mathrm{p}<0,01$ &
\end{tabular}

Korelasyon analizi sonucu değişkenler arasındaki ilişkiler incelendiğinde $\mathrm{p}<0,01$ anlamlılık düzeylerinde pozitif yönlü ilişkiler olduğu görülmektedir. Katılımcıların verdikleri cevaplara göre algılanan fayda $(0,702)$, bilgi kalitesi $(0,547)$, sistem kalitesi $(0,792)$ ve kullanıcı memnuniyeti $(0,695)$ değişkenlerinin kullanım ile arasında nispeten güçlü düzeyde, pozitif ve anlamlı bir ilişkinin olduğu söylenebilir. Buradan çıkarılacak sonuç uzaktan eğitim alan öğrencilerin bağımsız değişkenlere olan algılarının artması kullanıcı memnuniyetine ve kullanım olarak artıracağı yönündedir. Bu bulgular teknoloji kabul modeli ve bilgi sistemleri başarı modeli arasında pozitif yönlü önemli bir ilişkiye sahip olduğu yönündeki literatürde yer alan çalışma bulgularını da desteklemektedir (Roca vd., 2006; Shibly, 2011).

\section{Çoklu regresyon analizi sonuçları}

Teknoloji kabul modeli ve bilgi sistemleri başarı modeli değişkenlerinin kullanım boyutunun ne kadarlık kısmını açıklayabildiğini incelemek için çoklu regresyon analizi yapılmıştır. Elde edilen sonuçlar Tablo 4'te gösterilmiştir. 
Tablo 4: Değişkenler Arası Regresyon Analizine İlişkin Bulgular

\begin{tabular}{|l|l|l|l|l|l|}
\hline \multirow{2}{*}{} & \multicolumn{2}{|l|}{ R2=0,623 } & \multicolumn{3}{l|}{ Ayarlanmış R2=0,541 } \\
\cline { 2 - 6 } & \multicolumn{2}{|l}{$\mathrm{F}=41,425$} & \multicolumn{2}{l|}{ P değeri= ,000 } \\
\cline { 2 - 6 } Model & B & Std. Hata & Beta & $\mathrm{t}$ & P. Değeri \\
\hline Sabit & 1,148 &, 265 & & 5,147 &, 047 \\
\hline Sistem Kalitesi &, 192 &, 085 &, 217 & 2,743 &, 011 \\
\hline Bilgi Kalitesi &, 417 &, 066 &, 253 & 2,397 &, 018 \\
\hline Algılanan Fayda &, 054 &, 047 &, 081 & 1,522 &, 039 \\
\hline Bağımlı Değişken: Kullanıcı Memnuniyeti \\
\hline \multicolumn{7}{|l}{} \\
\hline
\end{tabular}

Kurulmuş olan regresyon modelinin istatistiksel olarak anlamlı olduğu görülmektedir $(F=41,425$; p $<0,05)$. Bağımsız değişkenler olan sistem kalitesi, bilgi kalitesi ve algılanan fayda bağımlı değişken kullanım memnuniyetinin \%54 oranında açıkladığı görülmektedir. Bağımsız değişkenler ile bağımlı değişken arasında orta derecede bir ilişki olduğu görülmektedir $(R 2=0,623 ; p<0,05)$. Standardize edilmiş katsayılar $(\beta)$ dikkate alındığında kullanım memnuniyetini açıklayan boyutların önem sırası sistem kalitesi, bilgi kalitesi ve algılanan fayda şeklinde sıralanmaktadır. Sistem kalitesi, bilgi kalitesi ve algılanan faydanın kullanım memnuniyeti üzerinde anlamlı bir etkiye sahip olduğunu söyleyebiliriz. Bu bulgular çerçevesinde H1, H2, H3 hipotezleri kabul edilmiştir. Bu bulgular literatürdeki teknoloji kabul modeli değişkenleri ve bilgi sistemleri başarı modeli değişkenlerinin kullanım memnuniyeti üzerindeki anlamlı etkilerinin bulunduğu araştırmalar ile tutarlılık göstermektedir (Bailey ve Pearson, 1983; Plouffe vd., 2006; Nagy, 2018; Adeyemi ve Issa, 2020).

Tablo 5: Kullanıcı Memnuniyetinin Kullanım Başarısı Üzerindeki Etkisi

\begin{tabular}{|c|c|c|c|c|c|}
\hline \multirow[b]{3}{*}{ Model } & \multicolumn{2}{|c|}{$\mathrm{R} 2=0,412$} & \multicolumn{3}{|c|}{ Ayarlanmış R2 $=0,390$} \\
\hline & \multicolumn{2}{|c|}{$F=51,458$} & \multicolumn{3}{|c|}{ P değeri $=, 000$} \\
\hline & B & Std. Hata & Beta & $\mathrm{T}$ & P. Değeri \\
\hline Sabit & 1,524 & ,247 & & 4,245 &, 000 \\
\hline Kullanıcı Memnuniyeti & ,711 & ,075 & ,636 & 7,274 & ,000 \\
\hline
\end{tabular}

Kurulan modelin istatistiksel olarak anlamlı olduğu $(\mathrm{F}=51,458 ; \mathrm{p}<0.05)$ saptanmıştır. Uzaktan eğitim sisteminin kullanıcı memnuniyetinin kullanım başarısını araştırdığımız modelde bağımsız değişken olan kullanım memnuniyeti $(\beta=0,636 ; p<0,05)$, bağımlı değişken kullanım başarısını pozitif yönde etkilediği ve bu etkinin istatistiki olarak güçlü olduğu görülmektedir. Kullanıcı memnuniyetinin kullanım başarısını \%39 oranında açıkladığı görülmektedir. Kullanım başarısını etkileyen başka faktörlerinde olduğu anlaşılmaktadır. Bu sonuca göre $\mathrm{H} 4$ hipotezi kabul edilmiştir.

\section{Sonuç ve tartışma}

Bu çalışma kapsamında COVID-19 pandemi süreci zorunlu uzaktan eğitim faaliyetlerinin öğrencilerin kabul ve reddine yönelik tutumları araştırılmış, birleştirilmiş TKM ve BS Başarı modeli ile öğrenci algısı, kabul ve red sebepleri açıklanmıştır. Yeni normal olarak ifade edilen pandemi kuralları öğrencilerin aktif öğrenme süreçlerini uzaktan takip etme zorunluluğu getirmektedir. Bu durumun ise dijital adaptasyon, sistem kullanımı ve sistemin kabulü ile doğrudan ilişkili olduğu yapılan analizler neticesinde görülmektedir.

Bu çalışma kapsamında elde edilen verilere göre uzaktan eğitimin faydalı olduğuna yönelik görüş yaklaşık \%50 oranında desteklenmiştir. Yapılan araştırmalarda da benzer sonuçlara ulaşılmış, uzaktan eğitimin faydalı olduğu yönünde \%45'lik bir sonuca ulaşıldığı tespit edilmiştir (Yiğit vd., 2010; Keskin ve Özer Kaya, 2020). Düzenli internete ulaşım, kişisel bir bilgisayara sahip olma, kayıttan olan derslerin öğrenciler tarafından tamamının izlenmesi gibi sorulara verilen cevaplar yaklaşık olarak \%50 civarında olumlu görüş etrafında kümelenmektedir. Geriye kalan \%50'nin ise sorulara olumsuz cevap verdiği görülmektedir. Bu durum ne yazık ki zorunlu uzaktan eğitim sürecine öğrencilerin fiziki şartlar çerçevesinde yeterince hazır olmadığı yönünde bir kanaat oluşturmaktadır. Ancak burada öğrencilerin uzaktan eğitimin faydasına inanmayan diğer \%50'lik kesimi de dikkate alınmalıdır. Bu durumun nedenlerinin derinliğine ve nitel çalışmayla araştırılması düşünülebilir. Ders videolarının tamamını 
izleyenlere yöneltilen diğer bir soru ise "dönem sonu sınavlarının ödev şeklinde olması dersleri takip etmenizi etkiledi mi?" şeklindeki soruya verilen cevaplara göre ise katılımcıların sadece \% 36 'sı bu durumdan olumsuz etkilendiğini ifade etmektedir. Sınavların ödev şeklinde yapılıyor olması katılımcılar açısından dersleri takip etmeye gerek duyulmayacağı yönünde bir algi kısmen de olsa oluşturduğu görülmektedir. Buluk ve Eşitti (2020) turizm öğrencilerine yapmış oldukları çalışmada öğrencilerin büyük çoğunluğunun dersleri takip ettiği sonucuna ulaşılmış ve memnuniyetlerinin daha fazla olduğu yönünde sonuca ulaşılmıştır.

Yine çalışma kapsamında uzaktan eğitimin kalite özellikleri için sistem kalitesi ve bilgi kalitesi bileşenleri kullanılmıştır. Ayrıca öğrencilerin algılarını anlamaya yönelik algılanan fayda değişkeni soruları sorulmuş bu sayede öğrencilerin sistem kullanımları ve kullanıcı memnuniyeti incelenmiştir. Yapılan regresyon analizleri sonucunda bilgi kalitesi, sistem kalitesi ve algılanan fayda değişkenlerinin kullanıcı memnuniyeti üzerinde anlamlı bir etkisi olduğu görülmüştür. Kullanım memnuniyeti üzerinde en güçlü etkiye sahip olan değişken ise sistem kalitesidir. Mevcut kullanımda olan eğitim platformu dikkate alındığında öğrencilerin sisteme bağlanma sorunu yaşadığını, senkron ve asenkron derslerde aşırı sistem girişi talebinden dolayı yavaşlama ve kesintilerin yaşandı̆̆ı göz önünde bulundurulduğunda bu sonucu desteklemektedir. Bilgi kalitesi ise gerekli içeriği sunabilmesi ve öğrencinin eğitim ihtiyacını karşılayabilmesi açısından kullanıcı memnuniyeti üzerinde etkili olmaktadır. Sisteme her yerden kolay ulaşılabilme, mobil cihazlar ile bağlanabilme imkânı, sistem arayüzünün anlaşılır olması gibi faktörler algılanan faydayı olumlu etkilemektedir. Çelik ve Sökmen (2018), Pal ve Vanijja (2020), Al-Okaily (2020), Rizun ve Strzelecki (2020), Pho vd. (2020), Al-Maroof vd. (2020) gibi araştırmacılar yaptıkları çalışmalarda algılanan fayda, sistem kalitesi ve bilgi kalitesi değişkenlerinin kullanım memnuniyeti üzerinde etkisini tespit etmişlerdir. Bu yönüyle çalışmada elde edilen sonuçlar literatür ile benzer sonuçlar vermektedir.

Kullanım değişkenini doğrudan etkileyen tek değişkenin kullanıcı memnuniyeti olduğu düşünüldüğünde ise kullanıcı memnuniyetini etkileyen unsurların iyileştirilmesi dolaylı olarak kullanım değişkenini olumlu etkileyeceği kanaatine varmamızı sağlamaktadır. Benzer bir sonuç da Çelik ve Sökmen (2018) tarafından bulunmuş, kullanıcı tatminin devam etme niyeti üzerinde olumlu etkisine ulaşıldığ ifade edilmiştir.

Bu çalışmada iki devlet üniversitesinin belirli bölümlerinden veri toplanmış ve çalışmanın bulgularına bu şekilde ulaşılmıştır. Araştırmanın sadece Dumlupınar ve Şeyh Edebali Üniversitelerinin belirli bölümlerinde yapılması kısıt olarak ifade edilmelidir. Uzaktan eğitim veren ve farklı platformlar kullanan özel ya da devlet üniversiteleri üzerinde daha farklı değişkenler eklenerek yeni bir çalışma yapılabilir ve bu sayede yeni normal olarak hayatımıza giren ve pandemi dönemi ve daha sonrasında sıklıkla başvuracak olduğumuz uzaktan eğitim sisteminin daha verimli olmasına imkân sağlayacaktır. Ayrıca bu çalışmadan elde ettiğimiz bulgulardan yola çıkarak nitel bir çalışma ile kullanııların uzaktan eğitimden memnun olmama sebepleri araştırılabilir.

Sonuç olarak, çalışmada ön plana çıkan faktörlerin de dikkate alınması sonucu öğrencileri uzaktan eğitime daha hızlı adapte olması ve daha etkin ve verimli öğrenme süreci planlanabilir. Pandemi döneminde uzaktan eğitim zorunluluğu, hem teknik alt yapıların geliştirilmesi ve teknolojik gelişmelere hazır olma anlamında hem de kullanıcıların uzaktan eğitim sistemlerini benimsemeleri ve daha etkin kullanmaları için bir fırsata dönüşebilir.

\section{Hakem Değerlendirmesi / Peer-review:}

Disş bağımsız

Externally peer-reviewed

\section{Çıkar Çatışması / Conflict of interests:}

Yazar(lar) çıkar çatışması bildirmemiştir.

The author(s) has (have) no conflict of interest to declare.

\section{Finansal Destek/ Grant Support:}

Yazar bu çalışma için finansal destek almadığını beyan etmiştir.

The author declared that this study has received no financial support. 


\section{Etik Kurul Onayı / Ethics Committee Approval:}

Bu çalışma için etik kurul onayı, Bilecik Şeyh Edebali Üniversitesi, Etik Kurulu/Komitesinden 07/07/2020 tarihli 54674167-050.01.04/ sayılı karar ile alınmıştır.

Ethics committee approval was received for this study from Bilecik Şeyh Edebali University, Ethics Committee on 07/07/2020 and 54674167-050.01.04/document number.

\section{Kaynakça / References}

Adeyemi, I. O., \& Issa, A. O. (2020). Integrating information system success model (ISSM) and technology acceptance model (TAM): Proposing Students' Satisfaction with University Web Portal Model. Record and Library Journal, 6(1), 69-79.

Ağaoğlu, E., İmer, G. \& Kurubacak, G. (2002). A case study of organizing distance education: Anadolu University, Turkish Online Journal of Distance Education-TOJDE, 3(1), 45-51.

Al-Maroof, R. S., Salloum, S. A.,Hassanien A. E. \& Shaalan, K. (2020). Fear from COVID-19 and technology adoption: the impact of Google Meet during Coronavirus pandemic, Interactive Learning Environments, DOI: 10.1080/10494820.2020.1830121

Al-Okaily, M., M Alqudah, H., Matar, A., Lutfi, A., \& Taamneh, A. (2020). Impact of COVID-19 Pandemic on acceptance of E-Learning System In Jordan: A Case of Transforming the Traditional Education Systems, Humanities \& Social Sciences Reviews,8(4), 840-851.

Amaro, S., Duarte, P., (2015). An integrative model of consumers' intentions to purchase travel online. Tourism Management, Vol. 46, ss. 64-79.

Ashill, N. and Jobber, D. (1999). The impact of environmental uncertainty perceptions, decision maker characteristics and work environment characteristics on the perceived usefulness of marketing information systems (MKIS): a conceptual framework. Journal of Marketing Management, 15, 519540.

Bailey, J. E., \& Pearson, S. W. (1983). Development of a tool for measuring and analyzing computer user satisfaction. Management science, 29(5), 530-545.

Bhattacherjee, A. (2001). Understanding information systems continuance: an expectation-confirmation model. MIS Quarterly, Vol:25, No:3, 351-370.

Bitner, M. J. (1990). Evaluating service encounters: the effects of physical surroundings and employee responses. Journal of Marketing, 54, 69-82.

Bozkurt, A. (2020). Koronavirüs (COVID-19) pandemi süreci ve pandemi sonrası dünyada eğitime yönelik değerlendirmeler: Yeni normal ve yeni eğitim paradigması. AUAd, 6(3), 112-142.

Chung, E., Subramaniam, G., \& Dass, L. C. (2020). Online Learning Readiness among University Students in Malaysia amidst COVID-19. Asian Journal of University Education, 16(2), 46-58.

Çelik, K. ve Sökmen, A. (2018). Uzaktan eğitime devam etme niyetinin anlaşılması: genişletilmiş teknoloji kabul modeli. Yönetim, Ekonomi ve Pazarlama Araştırmaları Dergisi, 2(3), 1-23.

Daniel, S. J. (2020). Education and the COVID-19 pandemic. Prospects, 1-6.

Davis, Fred. D.; Bagozzi, R. P. And Warshaw, P. R. (1989). User acceptance of computer technology: a comparison of two theoretical models. Management Science, 35(8), s. 982-1003.

DeLone, W. H., McLean, E. R. (1992). Information systems success: the quest for the dependent variable. Information Systems Research, 3, 60----95.

Devaraj, S., Fan, M., Kohli, R. (2002). "Antecedents of B2C channel satisfaction and preference: validating e-commerce metrics", Information Systems Research, Vol:13, No:3, 316-333.

Dhawan, S. (2020). Online learning: A panacea in the time of COVID-19 crisis. Journal of Educational Technology Systems, 49(1), 5-22.

Efiloğlu Kurt, Ö. (2015). Üniversite öğrencilerinin uzaktan eğitime bakış açılarının teknoloji kabul modeli ve bilgi sistemleri başarı modeli entegrasyonu ile belirlenmesi. Uluslararası Alanya İşletme Fakültesi Dergisi, 7(3), 223-234. 
Gelişli, Y. (2015). Uzaktan eğitimde öğretmen yetiştirme uygulamaları: tarihçe ve gelişim, Eğitim ve Öğretim Araştırmaları Dergisi, Cilt:4 Sayı:3

Godoe, P., \& Johansen, T. (2012). Understanding adoption of new technologies: Technology readiness and technology acceptance as an integrated concept. Journal of European Psychology Students, 3(1).

Gülbahar, Y. (2012). E-öğrenme. 2. Baskı. Ankara: Pegem Akademi

Harting, K., \& Erthal, M. J. (2005). History of distance learning. Information technology, learning, and performance journal, 23(1), 35-44.

Hung, S.Y., Chang, C. M., (2005). User acceptance of WAP services: Test of competing theories. Computer Standards and Interfaces, 27(4), 359-370.

Jones, D. (1996). Computing by distance education: problems and solutions. ITiCSE '96 Proceedings of the 1st Conference on Integrating Technology into Computer Science Education. Barcelona, İspanya: 02-06 Haziran, 139-146.

Kahya, V. (2015). İnsan kaynakları bilgi sistemlerinin kullanımında etkili olan faktörlerin genişletilmiş teknoloji kabul modeli ile incelenmesi. Dumlupınar Üniversitesi Sosyal Bilimler Enstitüsü İşletme Anabilim Dalı Doktora Tezi.

Kaya, Z., Erden, O., Çakır, H., ve Bağırsakçı B. (2004). “Uzaktan eğitimin temelleri dersindeki uzaktan eğitim ihtiyacı ünitesinin web tabanlı sunumunun hazırlanması". The Turkish Online Journal of Educational Technology. 3(3): 165-175.

Keskin, M. \& Özer Kaya, D. (2020). COVID-19 sürecinde öğrencilerin web tabanlı uzaktan eğitime yönelik geri bildirimlerinin değerlendirilmesi. İzmir Kâtip Çelebi Üniversitesi Sağlık Bilimleri Fakültesi Dergisi, 5(2): 59-67

King, W. R., \& He, J. (2006). A meta-analysis of the technology acceptance model. Information \& management, 43(6), 740-755.

Korkmaz, G., \& Toraman, Ç. (2020). Are we ready for the post-COVID-19 educational practice? An investigation into what educators think as to online learning. International Journal of Technology in Education and Science (IJTES), 4(4), 293-309.

Lehman, J.D. \& Russell, J.D. (2006). Educational technology for teaching and learning. Upper Saddle River, New Jersey: Pearson Merrill Prentice Hall

Liao, C., Chen, J. and Yen, D. C., (2007), “Theory of planning behavior (PDT) and customer satisfaction in the continued use of e-service: An integrated model", Computers in Human Behavior, 23(6), 28042822.

Mathieson, K. (1991). Predicting user intentions: Comparing the technology acceptance model with the theory of planned behavior. Information Systems Research, 2(3), 173-191.

Moore, M. G. (1990). Background and overview of contemporary American distance education. Contemporary issues in American distance education (pp. xii-xxvi). New York: Pergamon Press.

Nagy, J. T. (2018). Evaluation of online video usage and learning satisfaction: An extension of the technology acceptance model. International Review of Research in Open and Distributed Learning, 19(1): 160-185.

Negüs, F. (2016). Örgün ve uzaktan eğitim lisans öğrencilerinin teknoloji kabulüne ilişkin tutumlari üzerine bir araştırma. İstanbul Journal of Social Sciences, S. 14.

Lehman, J.D. \& Russell, J.D. (2006). Educational Technology for Teaching and Learning. Upper Saddle River, New Jersey: Pearson Merrill Prentice Hall.

Nipper, S. (1989). Third generation distance learning and computer conferencing. In R. Mason \& A. Kaye (Eds.), Mindweave: Communication, computers and distance education, pp.63-73. Oxford, UK: Pergamon.

Oranburg, S. (2020). Distance education in the time of coronavirus: quick and easy strategies for professors. Duquesne University School of Law Research Paper No. 2020-02.

Pal, D. , \& Vanijja, V. (2020). Perceived usability evaluation of Microsoft Teams as an online learning platform during COVID-19 using system usability scale and technology acceptance model in India. Children and Youth Services Review, 119, 105535 
Park, S. Y. (2009). An analysis of the technology acceptance model in understanding university students' behavioral intention to use e-learning. Journal of Educational Technology \& Society, 12(3), 150-162.

Park, E., Kim, H., \& Ohm, J. Y. (2015). Understanding driver adoption of car navigation systems using the extended technology acceptance model. Behaviour \& Information Technology, 34(7), 741-751.

Plouffe, C. R., Hulland, J, S. and Vandenbosch, M. (2001). Researchreport: richness versus parsimony in modeling technology adoption decisions-understanding merchant adoption of a smartcard-based payment system. Information Systems Research, 12(2), 208-222.

Pho, D.-H.; Nguyen, X.-A.; Luong, D.-H.; Nguyen, H.-T.; Vu, T.-P.-T.; Nguyen, T.-T.-T. (2020). Data on Vietnamese students' acceptance of using VCTs for distance learning during the COVID-19 pandemic. Data, 5, 83.

Ramayah, T., Lee, J. W. C. (2012). System characteristics, satisfaction and e-learning usage: A structural equation model (SEM). TOJET: The Turkish Online Journal of Educational Technology, 11(2).

Rizun, M.; Strzelecki, A. (2020). Students' acceptance of the COVID-19 impact on shifting higher education to distance learning in Poland. Int. J. Environ. Res. Public Health, 17, 6468.

Roca, J. C., Chiu, C. M., \& Martínez, F. J. (2006). Understanding e-learning continuance intention: An extension of the Technology Acceptance Model. International Journal of Human-Computer Studies, 64(8), 683-696.

Seddon, P., and S. Yip, (1992). An empirical evaluation of user information satisfaction (UIS) measures for use with general ledger account software. Journal of Information Systems, 6: 75-92.

Seddon, P. B. (1997). A respecification and extension of the Delone \& McLean model of IS Success. Information Systems Research, pp. 240-253.

Shibly, H. (2011). Human Resources Information Systems Success Assessment: An İntegrative Model. Australian Journal of Basic And Applied Sciences, 5(5): 157-169.

Sun, H. and Zhang, P. (2006). The role of moderating factors in user technology acceptance. International Journal of Human-Computer Studies, 64(2), 53-78.

Taylor, S., \& Todd P. (1995). Assessing IT Usage: the role of prior experience. MIS Quarterly, 19(4), 561570.

Taylor, S. \& Todd, P. (1995b). Understanding information technology usage: A test of competing models. Information Systems Research, 6(2), 144-76.

Telli Yamamoto, G., \& Altun, D. (2020). Coronavirüs ve çevrimiçi (online) eğitimin önlenemeyen yükselişi. Üniversite Araştırmaları Dergisi, 3(1), 25-34.

Venkatesh, V., Morris, M. G., Davis, G. B. and Davis, F. D., (2003), "User acceptance of Information Technology: toward a unified view", MIS Quarterly, 27(3), 425-78.

Wotto, M. (2020). The future high education distance learning in Canada, the United States, and France: Insights from before COVID-19 secondary data analysis. Journal of Educational Technology Systems, 49(2), 262- 281

Yiğit T., Bingöl O., Armağan H., Çolak, R., Aruğaslan, E. Yakut, G., Çivril, H. (2010). Öğrenci ve Öğretim Elemanının Uzaktan Eğitime Bakış Açısı. Akademik Bilişim 10-XII. Akademik Bilişim Konfersansı, Muğla. s.27-32

Yılmaz İnce, E., Kabul, A., \& Diler, İ. (2020). Distance education in higher education in the COVID-19 pandemic process: A case of Isparta Applied Sciences University. International Journal of Technology in Education and Science (IJTES), 4(4), 343-351.

Yükseköğretim Kurulu (YÖK) (2020a). Basın açılaması, https://www.yok.gov.tr/Sayfalar/Haberler/2020/, Erişim tarihi: 26.03.2020

Yükseköğretim Kurulu (YÖK) (2020b). Basın açıklaması, https://www.yok.gov.tr /Sayfalar/Haberler/2020/universitelerde-uygulanacak-uzaktan-egitime-iliskin-aciklama.aspx

Zaied, A. N. H. (2012). An integrated success model for evaluating information system in public sectors. Journal of Emerging Trends in Computing and Information Sciences, VOL. 3, NO. 6, July. 